\title{
Utilizando o MASP na Indústria de Louça Sanitária como Ferramenta de Melhoria de Resultados
}

\author{
Using MASP in the Sanitary Ware Industry as a Tool to Improve Results
}

Rodrigo Lima ${ }^{1,2}$ orcid.org/0000-0002-9902-7777

Luis Barros ${ }^{1,2}$

${ }^{1}$ Escola Politécnica de Pernambuco, Universidade de Pernambuco, Recife, Brasil,

2 Pós-graduação em Gestão da Qualidade e Produtividade, Escola Politécnica de Pernambuco, Pernambuco, Brasil.

E-mail do autor principal: Rodrigo Lima rodrigo.lima1979@hotmail.com

\section{Resumo}

O estudo tem por objetivo apresentar a utilização do Método de Análise de Solução de Problemas (MASP) na indústria de fabricação de louça sanitária de uma empresa de grande porte atuante em vários países do mundo. Na primeira etapa, será apresentado o modelo e material para capacitação das equipes de trabalho, neste momento será definido as unidades e equipes para implantação da metodologia. A segunda prevê o acompanhamento e desdobramento dos trabalhos de cada grupo, visando identificar o ganho de resultados e melhoria nos processos de fabricação de louça sanitária.

Palavras-Chave: Aplicação do Kaizen na fabricação de louça sanitária.

\begin{abstract}
The study aims to present the use of Troubleshooting Analysis Method (MASP) in the sanitary ware manufacturing a large company active in many countries worldwide industry. In the first stage, the model and material for training of work teams will be presented at this time is set units and teams for implementation of the methodology. The second provides for the monitoring and deployment of the work of each group, to identify the gain and improved results in sanitary ware manufacturing processes.
\end{abstract}

Key-words: Application of Kaizen in the manufacture of sanitary ware. 


\section{Introdução}

Na história das organizações, cada vez mais os gestores tem trabalhado para implementar, manter, controlar e melhorar os processos organizacionais. $\mathrm{Na}$ era do conhecimento, frente à globalização, a gestão de processos torna-se o grande diferencial para o sucesso das organizações.

No Brasil, a competitividade vem mudando o foco da gestão nas empresas, que tentam se adaptar aos novos tempos. Diante deste cenário competitivo, não só para as organizações privadas, as empresas públicas têm procurado implantar novas práticas gerenciais, destacando-se a gestão por processos.

Neste contexto, um fabricante de Louça Sanitária identifica a necessita de acompanhar tais mudanças, no campo gerencial, que ocorrem com uma velocidade cada vez maior. Na área de controle da produção o monitoramento eficaz dos processos influencia diretamente no cumprimento da missão institucional da empresa. Estrategicamente, foi criado um grupo de trabalho responsável pela condução da melhoria dos processos da referida Organização.

Para que o grupo de trabalho execute eficazmente o seu trabalho, há a necessidade de manter um controle efetivo dos processos organizacionais por meio de ferramentas gerenciais consagradas no ambiente corporativo. Esse controle apresenta-se como um ativo estratégico imprescindível para o atendimento da missão institucional.

O presente estudo, portanto, subsidiou o fabricante de Louça Sanitária, a identificar as principais contribuições no processo de fabricação com a aplicação do Kaizen. Com isso, o fabricante dispôs de parâmetros gerenciais para o balizamento de ações no tocante a adoção padronizada desta ferramenta nos setores subordinados, desta forma, permitindo a melhoraria da eficácia no desempenho dos processos organizacionais.

Primeiramente 0 trabalho apresenta as abordagens conceituais e as principais correntes teóricas referentes ao Kaizen, MASP e gestão da qualidade. A segunda parte apresenta a metodologia que foi empregada no desenvolvimento prático do trabalho, à maneira como foi utilizada a prática de Kaizen e os resultados obtidos.

Por fim, foram apresentados os resultados do primeiro ciclo de Kaizen, sua análise e discussão, encerrando com as conclusões e recomendações de estudos futuros para o aprofundamento do tema em questão.

\subsection{Justificativa}

O aumento significativo do consumo de louça sanitária em todo o território nacional tem requerido por parte do fabricante, no Brasil, um nível cada vez maior de especialização e qualidade dos produtos fornecidos à sociedade. Isso requer, por parte da organização, um controle cada vez mais eficaz dos processos organizacionais, compatíveis com o cenário de exigências de mercado. Daí a importância de se identificar as contribuições que podem ser trazidas por ferramentas gerenciais como o Kaizen e - MASP na fabricação de louça sanitária, tornando os processos organizacionais mais confiáveis e eficazes neste segmento.

Do ponto de vista estratégico, o fabricante poderá dispor, por meio desta pesquisa, de informações que poderão subsidiá-lo no que diz respeito à melhoria dos processos no controle da fabricação de louça sanitária sob a sua responsabilidade, compatíveis com as exigências do mercado, aumentando assim o nível de segurança do gerenciamento operacional.

Diante do exposto, evidencia-se que este trabalho busca contribuir, significativamente, com o fabricante e com a sociedade, disponibilizando informações de modo a garantir um controle eficaz dos processos organizacionais, visando a aumentar a segurança e a qualidade dos produtos fornecidos ao mercado brasileiro.

\subsection{Descrição do problema}

A identificação do problema se deu a partir do monitoramento dos baixos resultados globais e inconsistências dos dados que são monitorados pelo departamento de produção de uma unidade fabril da empresa de Louça Sanitária. Esses resultados podem ter impactos na saúde financeira operacional, podendo gerar prejuízos à companhia.

Assim, diante desse risco, surgiu o questionamento, que se tornou a base da investigação deste trabalho, concretizado na seguinte questão: como a aplicação Kaizen, utilizando o MASP pode contribuir para a eficácia do 
desempenho do processo de fabricação de louça sanitária, reduzindo os erros.

\section{Objetivos}

\subsection{Objetivo Geral}

Demonstrar a aplicação do primeiro ciclo de Kaizen, no processo de fabricação de louça sanitária de uma unidade fabril nacional, para reduzir o índice de quebras de produtos acabados.

\subsection{Objetivos específicos}

Descrever o ambiente da organização e seus principais processos por meio da técnica de estudo de caso.

Avaliar a aplicação do MASP na organização e identificar suas contribuições para a melhoria contínua da qualidade.

Estabelecer as melhorias no processo de fabricação de louça sanitária utilizando o Kaizen.

Verificar a eficácia da aplicação do Kaizen no resultado global no processo de fabricação de louça sanitária de uma unidade fabril nacional.

\section{Marco teórico}

\subsection{Manufatura enxuta}

Após a II Guerra Mundial, quando a economia japonesa estava devastada, o presidente da Toyota Motor Company, Toyoda Kiichiro, decidiu aumentar sua produção e ultrapassar a dos Estados Unidos e da Europa. Taiichi Ohno, consultor de produção da Toyota, analisou seus concorrentes mundiais e concluiu que os japoneses deveriam reduzir e buscar eliminar os desperdícios com o objetivo de alcançar elevados patamares de produção, ou seja, fazer uma empresa enxuta. A partir desse ponto, começou-se a pensar na Manufatura Enxuta (ME), a qual foi inicialmente denominada de Sistema Toyota de Produção (STP).

Em meados da década de 50 , os japoneses realizaram algumas visitas a montadoras de automóveis nos Estados Unidos. Eiji Toyoda e Taiichi Ohno perceberam que o sistema de produção em massa, que possui um alto volume de produção com pouca variedade de produtos, baixos custos e acima de tudo, onde a produção é empurrada ao mercado, não funcionaria no Japão por certas restrições que o país enfrentava. Além disso, a economia japonesa estava devastada com um crescimento muito baixo ou praticamente estagnada. Os trabalhadores japoneses não estavam acostumados a serem explorados ao máximo com trabalhos temporários, repetitivos, monótonos e sem autonomia por parte dos operários.

Vale salientar que no Japão os sindicatos eram fortes e organizados, não permitindo essas condições extrativas e precárias de trabalho. Então, a necessidade de produzir de forma diversificada e em pouca quantidade, com um maior rendimento dos trabalhadores, eliminando o desperdício e com baixos custos era uma questão de sobrevivência para a Toyota Motor Company. Então, logo após a II Guerra Mundial, nasceu o Sistema Toyota de Produção que, mais tarde, em meados de 1980, seria denominado Manufatura Enxuta.

O termo enxuta, do inglês Lean, foi definido por John Krafcik, do MIT, Massachusetts Institute of Technology, para descrever as técnicas do sistema de produção, do sistema de trabalho e da política de recursos humanos. KRAFCIK (1988) chamou o sistema de enxuto pela redução de atividades relacionadas à produção em massa, como estoques menores no local de fabricação e menor espaço para a fabricação.

Eiji Toyoda e Taiichi Ohno apud WOMACK \& JONES (1996) foram os pioneiros em utilizar o pensamento enxuto na forma de relacionamento entre clientes e fornecedores, nas operações da produção e no desenvolvimento de novos produtos com a eliminação do desperdício, representado pela palavra japonesa MUDA [1].

A Manufatura Enxuta consiste em fazer cada vez mais, utilizando cada vez menos esforço humano, equipamentos, tempo e espaço, aumentando dessa forma a eficiência da produção pela eliminação dos desperdícios (MUDA) [1]. A Manufatura Enxuta dá ênfase ao trabalhador multifuncional, ao baixo inventário, seja ele em processo ou final, e à produção puxada pela demanda (clientes), ou seja, produzir os tipos de unidades necessárias, no tempo necessário e na quantidade necessária, sempre prezando pela qualidade assegurada, controle de qualidade e o respeito à condição humana. 


\subsection{Princípios e objetivos da manufatura enxuta}

Um dos maiores desafios com que se depara a administração durante a implantação de técnicas de Manufatura Enxuta (Lean Manufacturing) é garantir que alterações reais no comportamento aconteçam em todos os níveis da organização. Mesmo a equipe gerencial mais bem-intencionada, leal e respeitada, se não alcançar a adoção entusiástica das mudanças, ou seja, não pensar e agir de modo "enxuto", as novas técnicas não terão prosperidade. Sem um sólido programa de mudanças gerenciais perfeitamente entrelaçadas com o projeto de Manufatura Enxuta, assim como uma forte liderança, o projeto tenderá ao fracasso desde o seu início [1]. O próprio termo Manufatura Enxuta pode ser problemático, já que muitos trabalhadores vêm o termo enxuto como sinônimo de perda de emprego. A administração deve ver o mundo com os olhos daqueles que estão sendo chamados a adotar a iniciativa enxuta, e responder à simples questão que vem à mente de cada um dos envolvidos: "O que eu tenho a ver com isso?" Pesquisas têm mostrado que a pessoa mais adequada para responder essa questão para os operários é o seu supervisor. A Figura 1 mostra os princípios e objetivos da manufatura enxuta.

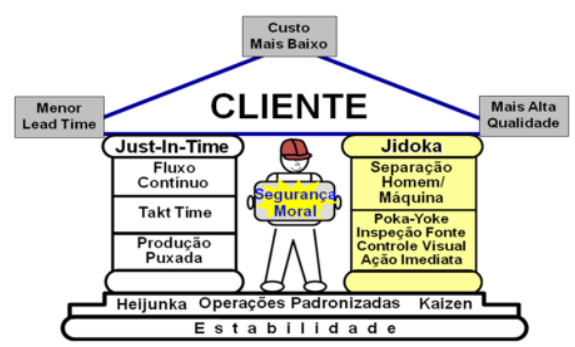

Figura 1: Princípios e objetivos da manufatura enxuta Fonte: Lean Manufacturing

\subsection{Kaizen}

O Kaizen foi criado no Japão após a II Guerra Mundial pelo engenheiro Taichi Ohno, com a finalidade de reduzir os desperdícios gerados nos processos produtivos, buscando a melhoria contínua da qualidade dos produtos e o aumento da produtividade. A palavra Kaizen significa "melhoria contínua". "Kai" significa mudar e "Zen" significa perfeição [1].

Segundo o Kaizen, todo o funcionário tem o poder de opinar sobre alguma melhoria que achar necessária em qualquer lugar da empresa. E como motivação, eles ganham prêmios. A Figura 2 apresenta o ideograma do Kaizen.

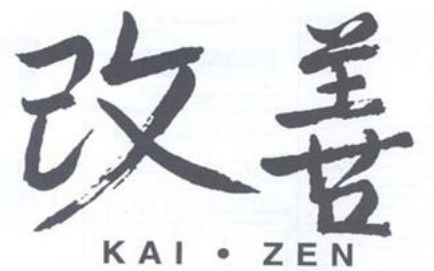

Figura 2: Ideograma da palavra Kaizen

Fonte: Lean Manufacturing

O Kaizen é considerado como uma ferramenta de melhoria contínua da qualidade, da tecnologia, dos processos, da cultura da empresa, da produtividade, da segurança e da liderança. O Kaizen está baseado na eliminação de desperdícios com base no bom senso, no uso de soluções baratas que se apóiem na motivação e criatividade dos colaboradores para melhorar a prática de seus processos de trabalho, com foco na busca pela melhoria contínua. É um sistema que engloba todos os funcionários da empresa, onde eles podem dar sua opinião a fim de melhorar algo em qualquer ambiente da empresa [1].

As melhorias aumentam a produtividade, a segurança e a eficácia, reduzindo o desperdício na empresa. Essas melhorias são pequenas e baratas, porém graduais e que somam grandes benefícios. Isso é mostrado nas Figuras 3 e 4.

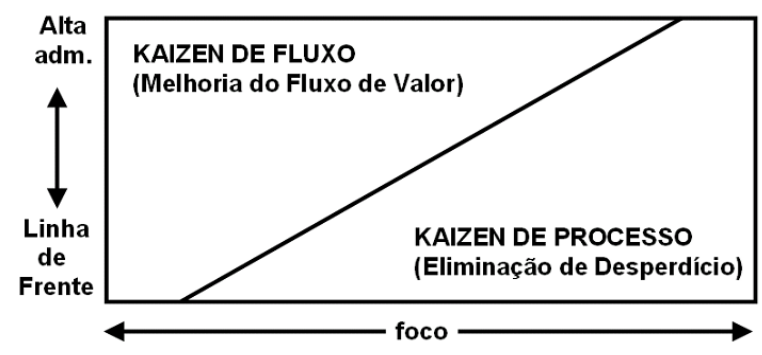

Figura 3: Dois níveis de Kaizen Fonte: Lean Manufacturing

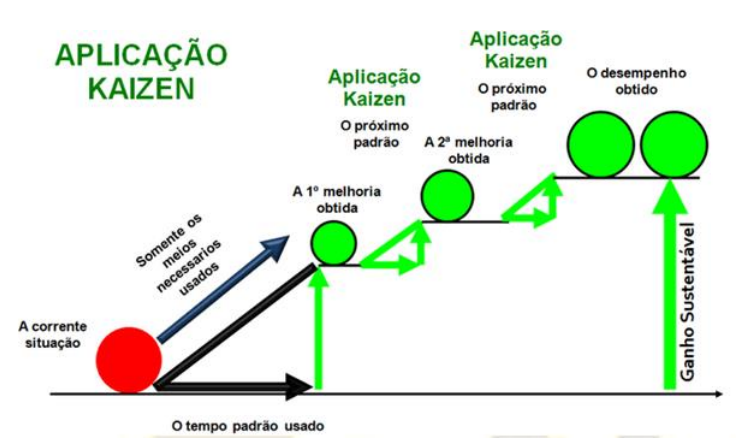

Figura 4: O que o Kaizen nos traz Fonte: Lean Manufacturing 


\subsection{PDCA}

O ciclo PDCA (Plan, Do, Check, Act), ciclo de Shewhart ou ciclo de Deming, é um ciclo de desenvolvimento que tem foco na melhoria contínua. Foi introduzido no Japão, sendo inicialmente utilizado para estatística e métodos de amostragem. O Ciclo PDCA nasceu no escopo da tecnologia TQC (Total Quality Control) como uma ferramenta que melhor representava o ciclo de gerenciamento de uma atividade. Um dos procedimentos mais bem conhecidos na gestão da qualidade total ou, em inglês, Total Quality Management (TQM) é o uso do ciclo PDCA [1].

Esse ciclo objetiva tornar mais claros, ágeis e eficientes os processos envolvidos na gestão, sendo de fundamental importância para a análise e melhoria dos processos organizacionais e para a eficácia do trabalho em equipe. Essa ferramenta é aplicada não apenas uma vez em determinado processo, mas sim sucessivas vezes, de forma continuada, para que a mudança seja concretizada e possa levar a novas melhorias, em loop, "girando o PDCA" para atingir o próximo momento.

O PDCA é aplicado para se atingir resultados dentro de um sistema de gestão e pode ser utilizado em qualquer empresa de forma a garantir o sucesso nos negócios, independentemente da área de atuação da organização. Mostrado na Figura 5.

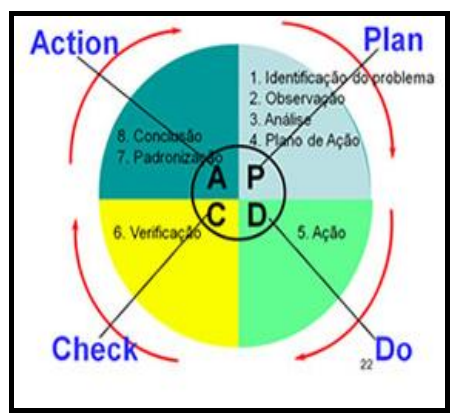

Figura 5: Ciclo PDCA

Fonte: CAMPOS, Vicente F., 2004.

\subsection{MASP (Método de Análise e Solução de Problemas)}

A Metodologia de Análise e Solução de Problemas é uma técnica sistemática de realização de ações corretivas e preventivas, visando eliminar causas de não conformidades ou anomalias em um processo, reduzindo os desperdícios e o retrabalho. É uma metodologia extremamente simples e prática que propicia a utilização das ferramentas da qualidade de forma ordenada e lógica, facilitando a análise de problemas, determinação de suas causas e elaboração de planos de ação para eliminação dessas causas.

100
Segundo CAMPOS (2004), um dos objetivos principais do MASP é eliminar as reincidências de não conformidades ou anomalias em um processo [1]. Arioli (1998), afirma que o MASP funciona como uma ferramenta eficiente para gerar melhorias, envolvendo um grupo de pessoas para tomar decisões, visando à qualidade dos produtos e serviços [2]. Já para Sampara (2009), o objetivo do MASP é elevar a probabilidade de solucionar um problema, onde a solução é um processo que segue uma sequência lógica e racional [3]. Segundo Ferreira (2010), este método para ser implantado deve seguir várias etapas, são elas: identificação do problema, observação, análise, planejamento da ação, ação, verificação, padronização e conclusão [4]. Ao seguir por todas as fases do ciclo PDCA, através das ferramentas da qualidade, o sistema de produção atinge um nível de qualidade superior, onde o surgimento de novos problemas será encarado como oportunidades de melhorias (TUBINO, 2009) [1].

Cada etapa, para ser executada, necessita de uma ou mais ferramentas da qualidade e de um grupo de pessoas inseridas em um projeto de trabalho com um objetivo de atingir uma meta. Neste contexto, Corrêa (2004) afirma que o fundamental é ter pessoas capacitadas e envolvidas, pois as ferramentas da qualidade apenas apóiam e auxiliam na tomada das decisões [5].

A seguir a Figura 6 lista as etapas e sub etapas do MASP baseado no PDCA.

\begin{tabular}{|c|c|c|c|}
\hline PDCA & FLUXOGRAMA & FASE & OBJETIVO \\
\hline \multirow{4}{*}{$\mathbf{P}$} & & $\begin{array}{l}\text { Identificaçẫo do } \\
\text { problema }\end{array}$ & $\begin{array}{l}\text { Definir claramente o problema e } \\
\text { reconhecer a sua importância. }\end{array}$ \\
\hline & & Observaçã̃o & $\begin{array}{l}\text { Investigar as características específicas } \\
\text { do problema com uma visẫo ampla e } \\
\text { sob vários pontos de vista. }\end{array}$ \\
\hline & & Análise & Descobrir as causas fundamentais. \\
\hline & & Plano de açẫo & $\begin{array}{l}\text { Conceber um plano para bloquear as } \\
\text { causas fundamentais. }\end{array}$ \\
\hline & & Açẫo & Eloquear as causas fundamentais. \\
\hline & & Verificação & Verificar se o bloqueio foi efetivo. \\
\hline & & $\begin{array}{l}\text { O bloqueio foi } \\
\text { efetivo? }\end{array}$ & \\
\hline \multirow{2}{*}{ A } & & Padronizaçẫo & $\begin{array}{l}\text { Prevenir contra o reaparecimento do } \\
\text { problema. }\end{array}$ \\
\hline & & Conclusão & $\begin{array}{l}\text { Recaptular todo o processo de solução } \\
\text { do problema para trabalho futuro. }\end{array}$ \\
\hline
\end{tabular}

Figura 6: Fases do MASP dentro do ciclo PDCA Fonte: Adaptado de CAMPOS, Vicente F., 2004.

\section{Metodologia}

O trabalho iniciou-se com uma análise bibliográfica relativo ao conceito e aplicação da http: / / dx.doi.org/10.25286/repa.v3i2.909 
Metodologia Manufatura Enxuta (Kaizen, PDCA, MASP).

Depois foi realizado o trabalho técnico, com o levantamento do histórico de erros.

Em seguida a execução das melhorias no processo e acompanhamento dos resultados.

\section{Aplicação do MASP}

Neste capitulo mostrar-se-á a aplicação do Kaizen utilizando o MASP ( 8 passos) para análise e solução de problemas e melhoria da confiabilidade no processo de fabricação de louça sanitária. A seguir a descrição de cada etapa do MASP no processo em estudo.

\subsection{Fase 1 - Identificação do problema}

A identificação do problema se deu a partir do acompanhamento do resultado global da unidade fabril que estava abaixo de $80 \%$ de eficiência, onde a empresa absorvia um custo pelo desperdício de aproximadamente $\mathrm{R} \$ 1.000 .000,00$ por mês. A eficiência projetada apresentava tendência desfavorável, podendo gerar ainda mais desperdício pela falta de qualidade na fabricação. Assim sendo, para mitigar prejuízos futuros definiu-se o mapeamento e análise dos problemas para uma estruturação na implementação das ações e busca contínua por melhores resultados de produtividade.

Para melhor aplicação do Kaizen estabeleceu-se grupos de trabalho com expertise técnica em cada processo, denominado Simbora Recife Figura 7 e Figura 8. Desta forma, as identificações dos problemas tornam-se mais adequados para cada etapa do processo de fabricação.

A definição dos defeitos para os produtos de louça sanitária são estabelecidos na norma ABNT NBR 15097 - Aparelho sanitário de material cerâmico - Requisitos e métodos de ensaio.

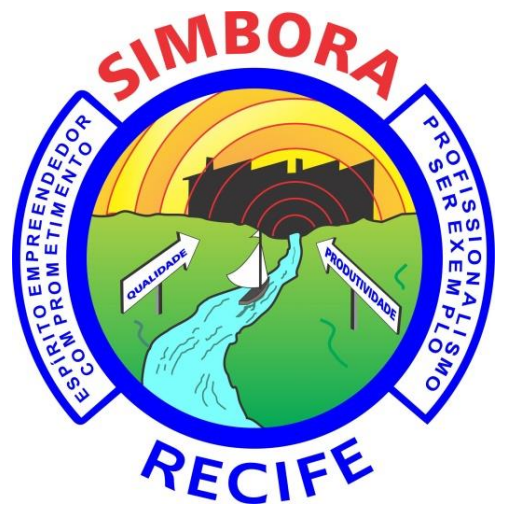

Figura 7: Identificação do Simbora Recife Fonte: Autor

\begin{tabular}{|l|}
\hline Grupo Vermelho \\
\hline Grupo Azul \\
\hline Grupo Laranja \\
\hline Grupo Preto \\
\hline Grupo Verde \\
\hline Grupo Lavanda \\
\hline
\end{tabular}

Figura 8: Grupos de trabalho do Simbora Recife Fonte: Autor

\subsubsection{Grupo vermelho}

O grupo vermelho é composto por profissionais responsáveis pela fabricação de bacias sanitárias convencionais. Este produto utiliza válvula hidráulica ou caixa de descarga a sua montante para o fornecimento de água, utilizada na remoção de dejetos humanos.

Após o mapeamento dos problemas definiu-se que a aplicação do Kaizen será na bacia convencional A e bacia convencional $B$ que apresenta um alto índice de quebra por racho.

\subsubsection{Grupo azul}

O grupo azul é composto por profissionais responsáveis pela fabricação de bacias sanitárias acopladas. Este produto utiliza caixa de descarga cerâmica a sua montante para o fornecimento de água, utilizada na remoção de dejetos humanos.

Após o mapeamento dos problemas definiu-se que a aplicação do Kaizen será na bacia acoplada $A$ e bacia acoplada B que apresenta um alto índice de quebra por racho.

\subsubsection{Grupo laranja}

O grupo laranja é composto por profissionais responsáveis pela fabricação de bacias sanitárias convencionais e acoplado de uma linha de produtos estratégica para a empresa. Estes produtos estão em uma categoria de mercado que garante uma maior rentabilidade a Organização e a manutenção da imagem da companhia por se tratar de produto com design e qualidade diferenciado.

Após o mapeamento dos problemas definiu-se que a aplicação do Kaizen será na bacia convencional $\mathrm{C}$ e bacia acoplada $\mathrm{C}$ que apresenta um alto índice de quebra por racho.

\subsubsection{Grupo preto}

O grupo preto é composto por profissionais responsáveis pela fabricação de colunas, lavatórios, 
caixas de descarga e acessórios. Estes produtos integram conjuntos cerâmicos para sala de banhos.

Após o mapeamento dos problemas definiu-se que a aplicação do Kaizen será na coluna integral.

\subsubsection{Grupo verde}

O grupo verde é composto por profissionais responsáveis pela gestão dos fornos de primeira queima dos produtos.

Após o mapeamento dos problemas definiu-se que a aplicação do Kaizen será na manutenção do pulmão de produtos para carregamento dos fornos.

\subsubsection{Grupo lavanda}

O grupo lavanda é composto por profissionais responsáveis pela requeima de produtos que na primeira queima necessitem de pequenos reparos, sem prejudicar o visual e resistência das peças.

Após o mapeamento dos problemas definiu-se que a aplicação do Kaizen será no processo de organização, posicionamento e controle de carregamento do forno de requeima.

\subsection{Fase 2 - Observação}

As observações do grupo de trabalho foram realizadas tendo como base as planilhas de controle de quebras por produto que são divulgados diariamente pelo setor de Planejamento e Controle da Produção (PCP) da empresa.

\subsubsection{Grupo vermelho}

A aplicação do Kaizen será na bacia convencional A e bacia convencional $B$ que apresenta um alto índice de quebra por racho DR, conforme Figura 9.

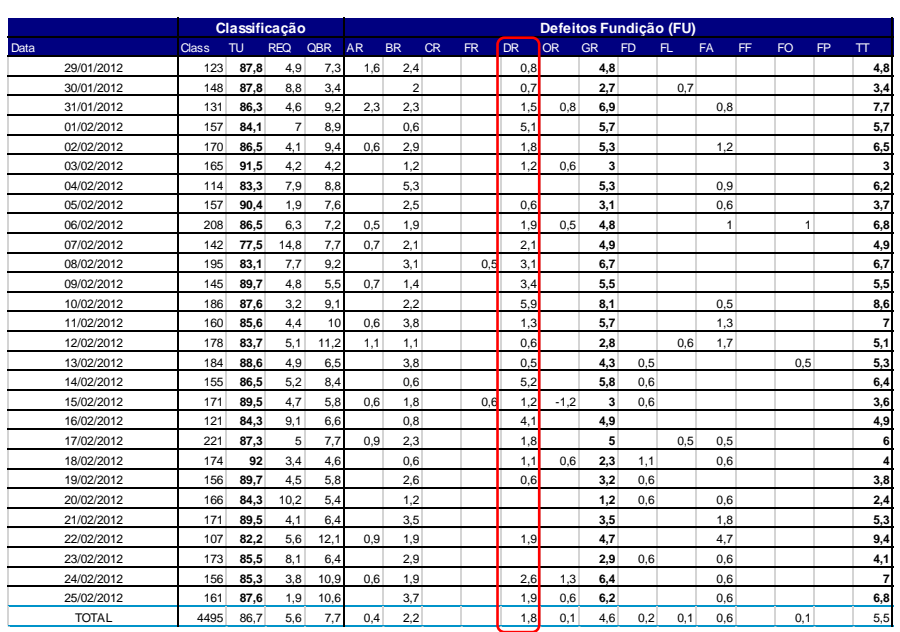

\subsubsection{Grupo azul}

A aplicação do Kaizen será na bacia acoplada A e bacia acoplada $B$ que apresenta um alto índice de quebra por racho DR, conforme Figura 10.

\begin{tabular}{|c|c|c|c|c|c|c|c|c|c|c|c|c|c|c|}
\hline \multicolumn{2}{|c|}{ Eficiência } & \multicolumn{4}{|c|}{ Defeitos Fase Crua (FC) } & \multicolumn{9}{|c|}{ Defeito 1a Queima (1aQ) } \\
\hline Produção & TU & AR & BR & FD & $\mathrm{MF}$ & $\mathbf{A R}$ & $\mathbf{B R}$ & FR & $\mathrm{DR}$ & OR & $\mathrm{FL}$ & FA & $\mathrm{FF}$ & $\mathrm{FO}$ \\
\hline 4038 & 96,8 & 0,5 & & 0,1 & 0,6 & 1 & 1,1 & 0,2 & 0,2 & 0,1 & 0,3 & 0,1 & & 0,1 \\
\hline 650 & 95,8 & & & 0,2 & 0,3 & 0,5 & 3,1 & & 0,2 & & 0,3 & 0,2 & & \\
\hline 3754 & 94,4 & 0,5 & & 0,1 & 0,6 & 0,5 & 3,4 & 0,1 & 0,6 & 0,1 & 0,5 & 0,2 & 0,1 & 0,1 \\
\hline 4207 & 94,4 & 0,7 & & 0,1 & 0,7 & 0,8 & 3,4 & 0,1 & 0,7 & & 0,5 & 0,1 & & \\
\hline 949 & 93,2 & 0,3 & & & 0,8 & 0,4 & 4 & & 1,3 & & 0,5 & 0,4 & & 0,1 \\
\hline 2683 & 91,4 & 0,3 & & & 0,3 & 0,8 & 4,8 & 0,3 & 1 & 0,1 & 1,1 & 0,1 & 0,3 & \\
\hline 3731 & 91,8 & 0,8 & & 0,2 & 0,9 & 0,8 & 4,6 & 0,3 & 0,7 & 0,1 & 1,2 & 0,3 & 0,2 & 0,1 \\
\hline 4029 & 90,8 & 0,3 & & 0,2 & 0,9 & 1,2 & 5,2 & 0,4 & 0,6 & 0,1 & 1,1 & 0,4 & 0,2 & \\
\hline 4031 & 90,3 & 0,8 & 0,1 & 0,3 & 0,4 & 1,3 & 5,6 & 0,1 & 0,6 & 0,1 & 1 & 0,5 & 0,1 & 0,3 \\
\hline 1335 & 91,2 & 2,8 & & 0,1 & 1,6 & 4,9 & 1,6 & 0,8 & 0,3 & & 0,3 & 0,7 & 0,1 & \\
\hline 325 & 87,4 & 1,2 & & 1,2 & 0,9 & 1,2 & 5,8 & 0,6 & 0,6 & 0,3 & 2,2 & 1,5 & 0,3 & \\
\hline
\end{tabular}

Figura 10: Mapeamento dos defeitos Grupo azul Fonte: Autor

\subsubsection{Grupo laranja}

Após o mapeamento dos problemas definiu-se que a aplicação do Kaizen será na bacia convencional $\mathrm{C}$ e bacia acoplada $\mathrm{C}$ que apresenta um alto índice de quebra por racho $\mathrm{CR}$, conforme Figura 11.

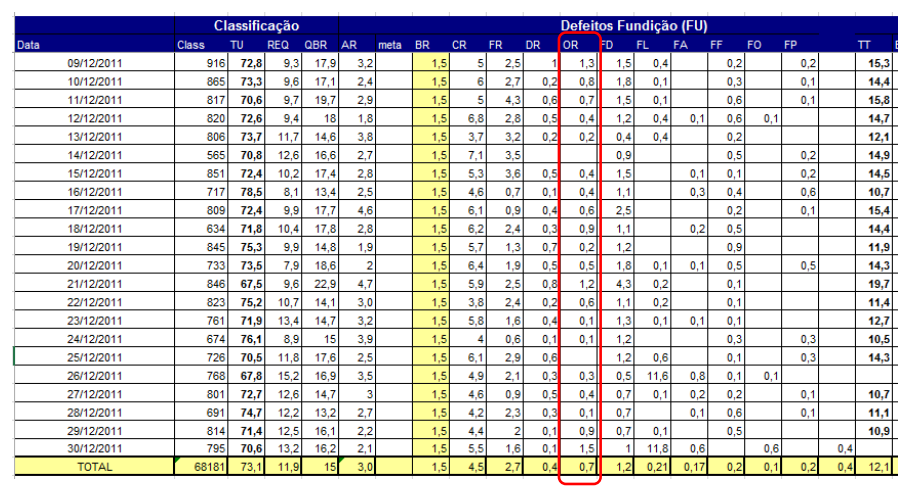

Figura 11: Mapeamento dos defeitos Grupo laranja Fonte: Autor

\subsubsection{Grupo preto}

A aplicação do Kaizen será na coluna integral que apresenta um alto índice de quebra por racho FR, conforme Figura 12.

Figura 9: Mapeamento dos defeitos Grupo vermelho Fonte: Autor 


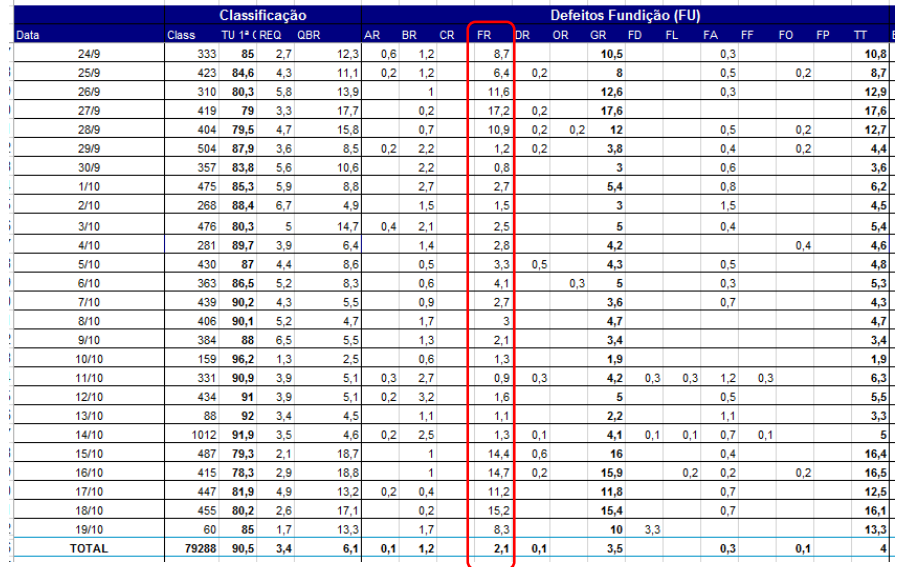

Figura 12: Mapeamento dos defeitos Grupo preto Fonte: Autor

\subsubsection{Grupo verde}

A aplicação do Kaizen será na manutenção do pulmão de produtos para carregamento dos fornos que apresenta um alto índice de quebra por CC e QS, conforme Figura 13.

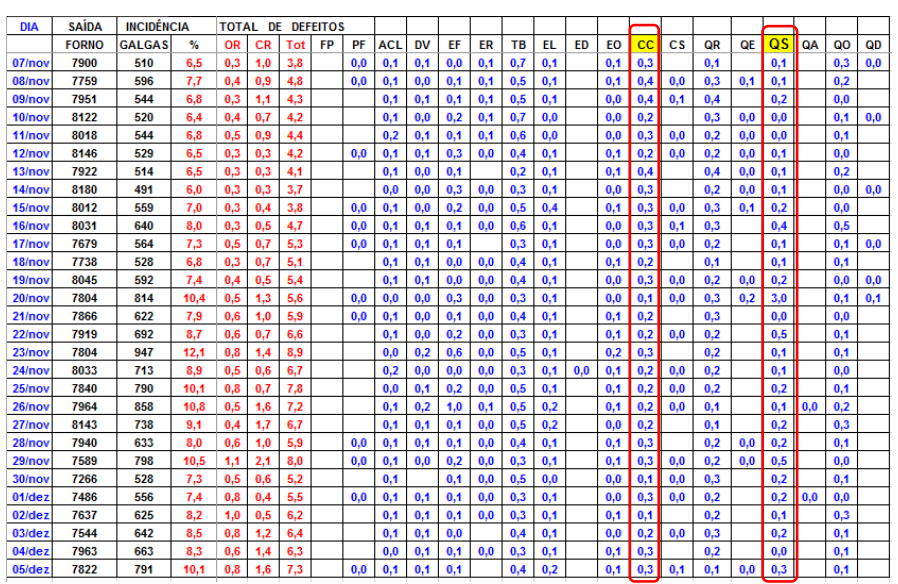

Figura 13: Mapeamento dos defeitos Grupo verde Fonte: Autor

\subsubsection{Grupo lavanda}

A aplicação do Kaizen será no processo de organização, posicionamento e controle de carregamento do forno de requeima que apresenta um alto índice de quebra por falta de limpeza $\mathrm{FL}$, conforme Figura 14.

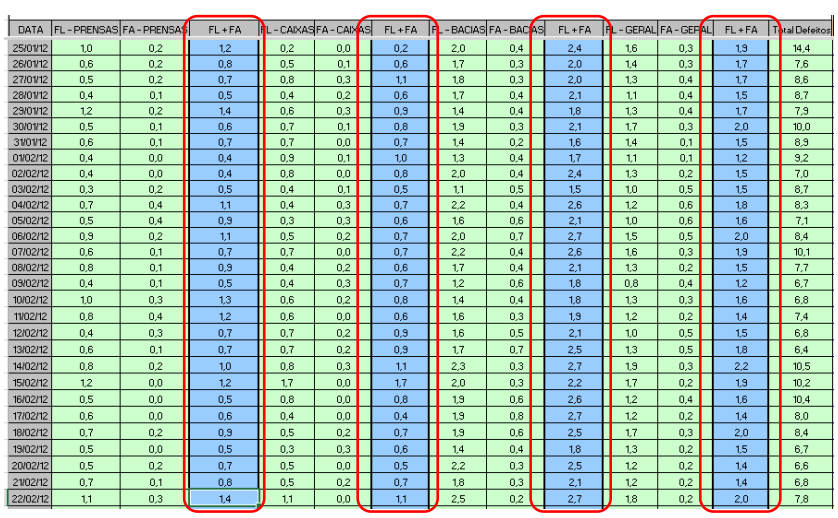

Figura 14: Mapeamento dos defeitos Grupo lavanda Fonte: Autor

\subsection{Fase 3 - Análise do processo}

Foram levantadas as principais causas, por meio de brainstorm com a equipe de cada grupo do Simbora Recife, sendo utilizado o diagrama de causa $x$ efeito.

\subsubsection{Grupo vermelho}

O grupo vermelho identificou que 0 destacamento e colagem da rolha do poço com a peça mole ocasionava a incidência do racho $D R$, conforme mapeamento dos $6 \mathrm{M}$ 's demonstrado na Figura 15.

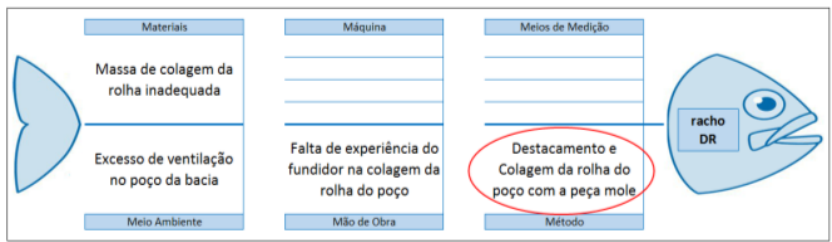

Figura 15: Definição da causa raiz do Grupo vermelho Fonte: Autor

\subsubsection{Grupo azul}

O grupo azul identificou que a falta de definição e padronização do Fifo (entrada e saída) do estoque de carregamento de peças cruas, encontrava-se inadequado para manutenção da carga dos fornos de primeira queima, desta forma ocasionava a incidência do racho DR, conforme mapeamento dos 6M's demonstrado na Figura 16.

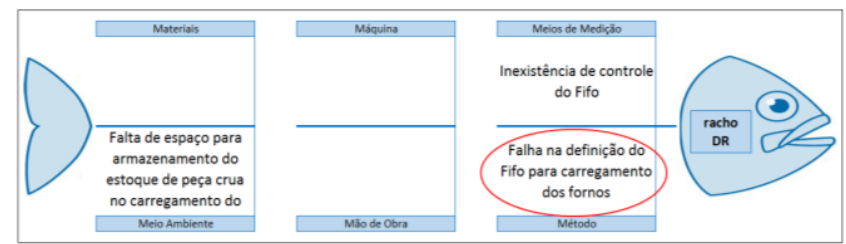


Figura 16: Definição da causa raiz do Grupo azul Fonte: Autor

\subsubsection{Grupo laranja}

O grupo laranja identificou que o excesso de ventilação nas bacias no processo de secagem ocasionava a incidência do racho $\mathrm{CR}$, conforme mapeamento dos 6M's demonstrado na Figura 17.

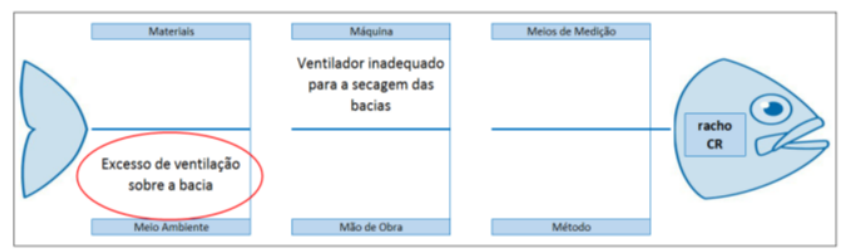

Figura 17: Definição da causa raiz do Grupo laranja Fonte: Autor

\subsubsection{Grupo preto}

O grupo preto identificou que a falta de inspeção e falha no processo de secagem dos produtos ocasionava a incidência do racho FR, conforme mapeamento dos 6M's demonstrado na Figura 18.

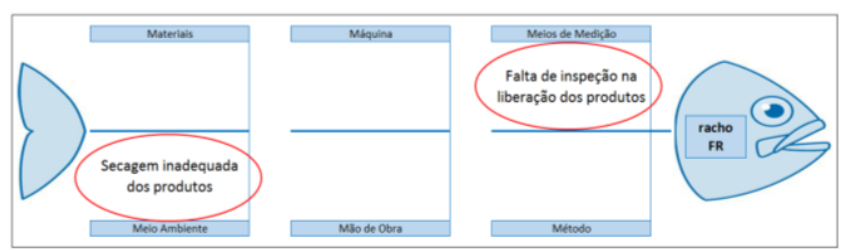

Figura 18: Definição da causa raiz do Grupo preto Fonte: Autor

\subsubsection{Grupo verde}

O grupo verde identificou que a falta de máquinas e limpeza inadequada nos produtos e em equipamentos ocasionava a incidência de QS, conforme mapeamento dos $6 \mathrm{M}$ 's demonstrado na Figura 19.

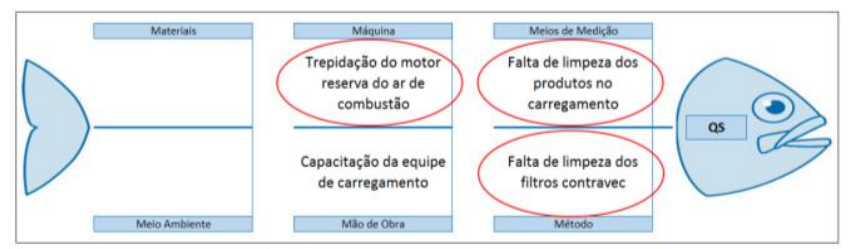

Figura 19: Definição da causa raiz do Grupo verde Fonte: Autor

\subsubsection{Grupo lavanda}

O grupo lavanda identificou que a falta de inspeções, treinamento e classificação das regiões dos defeitos ocasionavam a incidência de $\mathrm{FL}$, 104 conforme mapeamento dos $6 \mathrm{M}$ 's demonstrado na Figura 20.

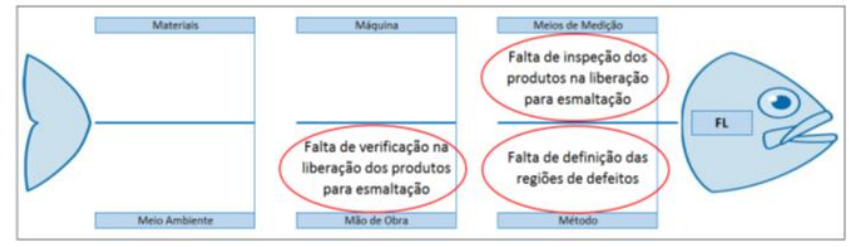

Figura 20: Definição da causa raiz do Grupo lavanda Fonte: Autor

\subsection{Fase 4 - Plano de ação}

Com a identificação das causas, os grupos de trabalho definiram plano de ação específico para a mitigação ou eliminação dos desvios. Os planos foram desenvolvidos em reuniões de Brainstorm, onde ações para contenção, correção e de melhoria foram estabelecidas. A padronização e divulgação das ações implementadas foram através de: revisão de procedimentos e reciclagem na capacitação da equipe operacional (onde estava concentrado o percentual de erros da estação).

\subsubsection{Grupo vermelho}

O grupo vermelho definiu o plano de ação conforme Figura 21.

\begin{tabular}{|c|c|c|c|}
\hline Ação & Como fazer & Responsável & Quando \\
\hline $\begin{array}{l}\text { Mudança do Passo na colagem do } \\
\text { peitinho. }\end{array}$ & $\begin{array}{l}\text { Mudança/Padronização da colagem do Peitinho após o } \\
\text { corte da saia e antes da lavagem da peça. Esperar } \\
\text { peça ficar mais firme para efetuar a colagem }\end{array}$ & Fundidor Lider & $18 / 01 / 2012$ \\
\hline $\begin{array}{l}\text { Todos passando mica na região } \\
\text { saida d'agua e embaixo do poço. }\end{array}$ & $\begin{array}{l}\text { Durante o destacamento e preparaçăo para próxima } \\
\text { fundição }\end{array}$ & Fundidor & $23 / 01 / 2012$ \\
\hline $\begin{array}{l}\text { Alterado o tempo de pressurização } \\
\text { em todas as bancas para } 25 \mathrm{~min}\end{array}$ & $\begin{array}{l}\text { Alterado no Painel e Verificado diariamente no check } \\
\text { list }\end{array}$ & Fundidor Lider & $23 / 01 / 2012$ \\
\hline
\end{tabular}

Figura 21: Plano de ação do Grupo vermelho Fonte: Autor

\subsubsection{Grupo azul}

O grupo azul definiu o plano de ação conforme Figura 22.

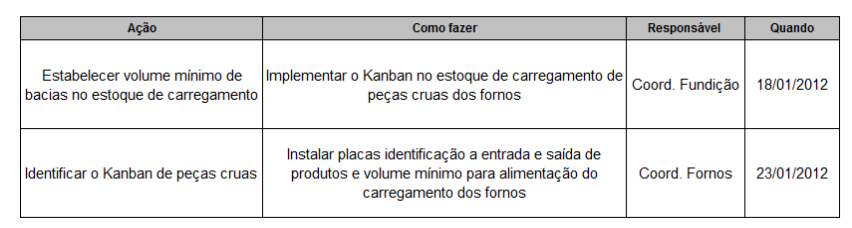

Figura 22: Plano de ação do Grupo azul Fonte: Autor

http: / / dx.doi.org/10.25286/repa.v3i2.909 


\subsubsection{Grupo laranja}

O grupo laranja definiu o plano de ação conforme Figura 23.

\begin{tabular}{|c|c|c|c|}
\hline Ação & Como fazer & Responsável & Quando \\
\hline Retirar ventilação das argolas & $\begin{array}{c}\text { Desligar o ventilador após o acabamento da segunda } \\
\text { fundição do lado da argola }\end{array}$ & Fundidor Lider & 06/02/2012 \\
\hline
\end{tabular}

Figura 23: Plano de ação do Grupo laranja Fonte: Autor

\subsubsection{Grupo preto}

O grupo preto definiu o plano de ação conforme Figura 24.

\begin{tabular}{|c|c|c|c|}
\hline Ação & Como fazer & Responsável & Quando \\
\hline $\begin{array}{c}\text { Melhorar o acabamentos dos } \\
\text { produtos }\end{array}$ & $\begin{array}{c}\text { Supervisor } \\
\text { Fundição }\end{array}$ & $15 / 08 / 2011$ \\
\hline $\begin{array}{c}\text { Utilizar ventiliação artinha nos locais criticos } \\
\text { secagem dos produtos }\end{array}$ & $\begin{array}{c}\text { Instalar ventiladores de teto nas esteiras de transporte } \\
\text { de produtos }\end{array}$ & $\begin{array}{c}\text { Supervisor } \\
\text { Fundição }\end{array}$ & $22 / 08 / 2011$ \\
\hline $\begin{array}{c}\text { Inspecionar os produtos antes de } \\
\text { liberar para esmaltaçãao }\end{array}$ & $\begin{array}{c}\text { Ainspeção deve ser efetuada em 100\% dos produtos } \\
\text { fabricados com o auxilio de cabines e ferramentas } \\
\text { especificas para cada tipo de peça. }\end{array}$ & $\begin{array}{c}\text { Supervisor } \\
\text { Fundição }\end{array}$ & $08 / 08 / 2011$ \\
\hline
\end{tabular}

Figura 24: Plano de ação do Grupo preto Fonte: Autor

\subsubsection{Grupo verde}

O grupo verde definiu o plano de ação conforme Figura 25.

\begin{tabular}{|c|l|c|c|}
\hline Ação & Como fazer & Responsável & Quando \\
\hline $\begin{array}{c}\text { Substituição do motor reserva do ar } \\
\text { de combustăo }\end{array}$ & $\begin{array}{c}\text { Adquirir e instalar novo motor reserva, atentar-se para } \\
\text { as caracterisiticas definidas pelo fabricante dos fornos. }\end{array}$ & $\begin{array}{c}\text { Gerente de } \\
\text { Produção }\end{array}$ & 07/10/2011 \\
\hline $\begin{array}{c}\text { Efetuar a limpeza dos produtos no } \\
\text { carregamento das vagonetas dos } \\
\text { fornos }\end{array}$ & $\begin{array}{l}\text { Soprar as peças no ato do carregamento para } \\
\text { eliminação de impurezas que possam impreguinas no } \\
\text { esmalte }\end{array}$ & $\begin{array}{c}\text { Supervisor } \\
\text { Fornos }\end{array}$ & 20/10/2011 \\
\hline $\begin{array}{c}\text { Efetuar a limpeza dos filtros } \\
\text { contravec }\end{array}$ & $\begin{array}{l}\text { Efetuar a limpeza dos filtros contravec e substituir o } \\
\text { servo motor e controlador do grupo V }\end{array}$ & $\begin{array}{c}\text { Supervisor } \\
\text { Fornos }\end{array}$ & 29/11/2011 \\
\hline
\end{tabular}

Figura 25: Plano de ação do Grupo verde Fonte: Autor

\subsubsection{Grupo lavanda}

O grupo lavanda definiu o plano de ação conforme Figura 26.

\begin{tabular}{|c|c|c|c|}
\hline Ação & Como fazer & Responsável & Quando \\
\hline $\begin{array}{l}\text { Definir inspeção das peças antes de } \\
\text { liberar para esmaltação }\end{array}$ & $\begin{array}{l}\text { Inspecionar } 100 \% \text { dos produtos antes de liberar para } \\
\text { esmaltação no carrossel. Utilizar cabines e } \\
\text { ferramentas especificas para auxiliar na visualização e } \\
\text { identificação dos defeitos. }\end{array}$ & $\begin{array}{l}\text { Supervisor } \\
\text { Fundição }\end{array}$ & $17 / 02 / 2012$ \\
\hline Reciclagem de profissionais & $\begin{array}{l}\text { Efetuar o treinamento de reciclagem dos retirados que } \\
\text { executam a inspeção dos produtos. Deve-se focar na } \\
\text { responsabilidade das constataçốs, ou seja, } \\
\text { negligência nesta verificaçãon não será aceita. }\end{array}$ & $\begin{array}{l}\text { Supervisor } \\
\text { Fundição }\end{array}$ & $22 / 02 / 2012$ \\
\hline Mapear as regiōes dos defeitos & $\begin{array}{l}\text { Estabelecer mapa dos defeitos criticos por região e } \\
\text { treinar os profissionais envolvidos. }\end{array}$ & $\begin{array}{l}\text { Supervisor } \\
\text { Métodos e } \\
\text { Processos }\end{array}$ & $17 / 02 / 2012$ \\
\hline
\end{tabular}

Figura 26: Plano de ação do Grupo lavanda Fonte: Autor

\subsection{Fase 5 - Ação}

As ações foram implementadas conforme planos de ações citados no capítulo anterior. O monitoramento do desempenho foi realizado através da coleta de dados por meio das folhas mensais de verificação.

Os resultados foram positivos com a execução das ações, pois de imediato houve redução das quebras no processo de fabricação, podendo ser evidenciado pelo acompanhamento dos índices dos mensais.

Para garantir a implementação das ações e melhorias estabeleceu-se Planos de Controle em todos os departamentos da empresa, sendo exemplificado pela Figura 27.

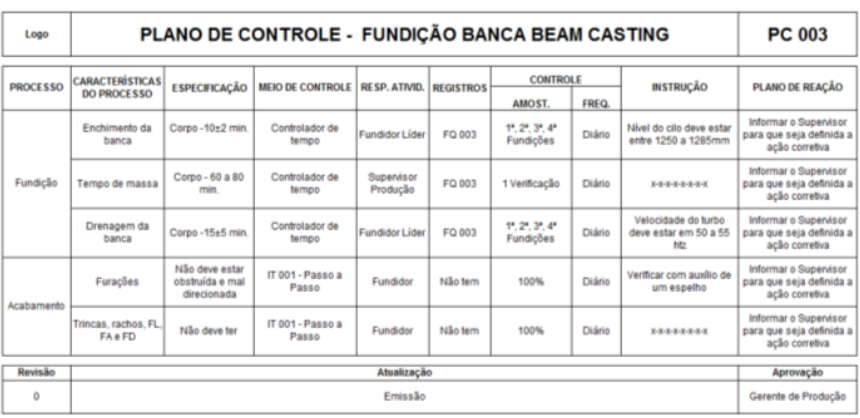

Figura 27: Plano de controle Fonte: Autor

\subsection{Fase 6 - Verificação}

Nessa fase definiu-se a sistemática de monitoramento da eficiência na fabricação dos produtos de louça sanitária. Intensificou-se nos produtos onde o primeiro ciclo de Kaizen foi aplicado. A verificação é feita através de coleta de dados nas folhas de verificação mensais. O fabricante de louça sanitária utiliza o Kaizen como ferramenta de trabalho e os grupos de trabalho do Simbora Recife para avaliação de performance de resultados e necessidade de correções, conforme exemplificado na Figura 28.

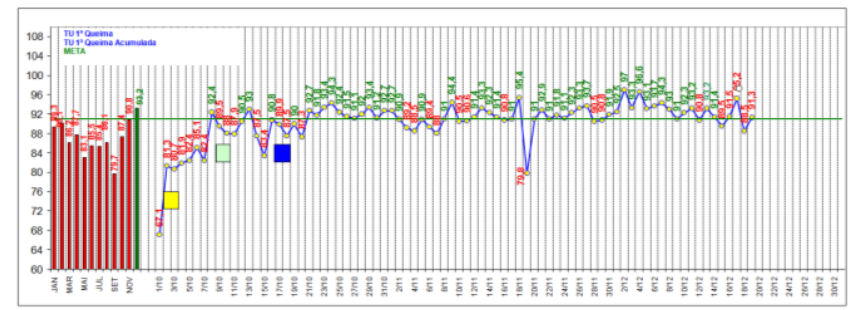

Figura 28: Controle estatístico de produção Fonte: Autor 
Os grupos de trabalho do Simbora Recife monitoram periodicamente a evolução através de reuniões periódicas, conforme Figura 29.

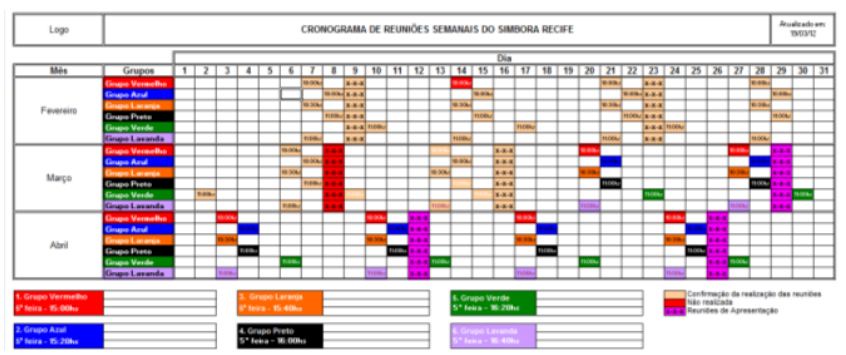

Figura 29: Cronograma de reuniões do Simbora Recife Fonte: Autor

\subsection{Fase 7 - Padronização}

A padronização das ações implementadas por cada grupo de trabalho do Simbora Recife, após o primeiro ciclo de aplicação do Kaizen, foi efetuada através da criação de Instruções de Trabalho específico para cada tipo de produto e processo, conforme exemplificado na Figura 30.

Este material permite que os profissionais que executam as atividades possam consultar o material e garantir a realização da atividade conforme planejado, evitando desvios que possam impactar a qualidade na fabricação.

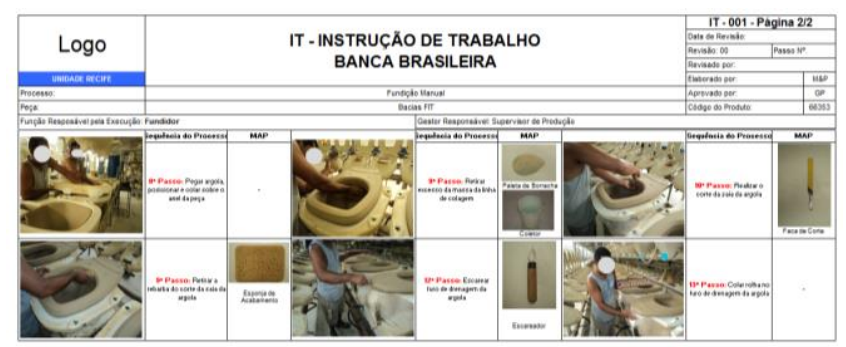

Figura 30: Instrução de Trabalho Fonte: Autor

\subsection{Fase 8 - Conclusão}

O trabalho revela que a aplicação do Kaizen associado a metodologia do MASP, mostrou-se eficaz na melhoria contínua do processo de fabricação de louça sanitária, sendo evidenciado as seguintes contribuições:

$\checkmark$ redução significativa de erros de fabricação;

$\checkmark$ elevação do nível de confiabilidade do processo; $\checkmark$ elevação do nível de eficácia do processo;

$\checkmark$ elevação do nível de segurança operacional;

$\checkmark$ mudança da meta de produtividade de $90 \%$ para $91 \%$, representando um ganho de $\mathrm{R} \$$ 84.000,00 mês;

$\checkmark$ melhoria da eficiência da unidade fabril de $80,00 \%$ para 90,80\%, evitando um desperdício de para $\mathrm{R} \$ 540.000,00$ mês com quebras no processo de fabricação de louça sanitária.

$\checkmark$ refinando o processo e criando um ativo intangível de ações proativas dos operadores, resultando em ações corretivas de não conformidades.

\section{Conclusão}

Este trabalho demonstrou a aplicação prática do Kaizen associado ao Método de Análise e Solução de Problemas (MASP), em uma unidade fabril de louça sanitária. As contribuições desta aplicação resultaram em ações de melhorias que reduziram, significativamente, erros oriundos da ineficiência de métodos e treinamentos no processo de fabricação.

Como em toda pesquisa desta natureza, faz-se necessário destacar algumas das limitações do trabalho, dentre elas não ter tido acesso aos dados do ano de 2012, visto o autor não fazer mais parte do quadro de empregados da organização estudada. Deve-se destacar que, apesar dessa limitação, os resultados obtidos na pesquisa não invalidam o alcance dos objetivos propostos, considerando que foi possível identificar claramente as contribuições da aplicação do MASP para execução de uma melhoria de processos, executando a filosofia Kaizen para redução do índice de erros em um processo operacional de fabricação de louça sanitária.

Levando em conta que este processo também existe nas demais empresas de louça sanitária que apresentam características semelhantes, infere-se que os resultados também poderão ser replicados a estes e em todo Brasil, servindo como aprendizagem organizacional, fundamento da excelência da gestão. Cabe ressaltar, de toda forma, que para confirmar a aplicação destes resultados às demais empresas, este estudo poderá servir de base para estudos futuros mais similares, por meio de uma pesquisa, abrangendo todas as empresas de fabricação do Brasil, com uma base amostral mais significativa. 
Isso possibilitará as empresas a ter subsídios para, a nível estratégico, implantar políticas de melhorias de gestão de processos, de acordo com as necessidades reais de cada companhia, o que garantirá um maior grau de qualidade e eficiência dos produtos fornecidos ao mercado brasileiro.

\section{Referências}

[1] CAMPOS, Vicente F. TQC - Controle da Qualidade Total (no estilo japonês). Belo Horizonte: Ed. INDG Tecnologia e Serviços, 2004.

[2] ARIOLI, E.E. Análise e solução de problemas: o método da qualidade total com dinâmica de grupo. 1 ed. Rio de Janeiro: Qualitymark, 1998. $340 \mathrm{p}$.

[3] SAMPARA, E.J.M; ADAMI, R. Análise de insumos e aplicação de sistemática de solução de problemas para geração de melhorias; Anais do ENEGEP XXIX - Encontro Nacional de Engenharia de Produção; 2009; Bahia; BRASIL; Português.

[4] FERREIRA, Laura Maria Leite. SANTOS, Marítiza Wanzeler. SILVA, Monica Gomes. MOREIRA, Bruna Brandão. Utilização do MASP, através do ciclo PDCA, para o tratamento do problema de altas taxas de mortalidade de aves no setor avícula, Anais. XXX ENEGEP, 2010.

[5] CORRÊA, Henrique L.; CORRÊA Carlos A. Administração de Produção e Operações, São Paulo, Atlas, 2004.

[6] BARROS, Luis C. Fo. Sistema de Qualidade Série ISO 9000. Recife. Escola Politécnica da UPE.

[7] IMAI, M. (1990). Kaizen: a estratégia para o sucesso competitivo. Tradução Cecília Fagnani Lucca. $3^{a}$ ed. IMAM.

[8] MARANHÃO, Mauriti; MACIEIRA, Maria Elisa Bastos. O processo nosso de cada dia: modelagem de processos de trabalho. 2. ed. Rio de Janeiro: Qualitymark Ed., 2010.

[9] WERKEMA, Maria Cristina Catarino. Ferramentas estatísticas básicas para o gerenciamento de processos. Belo Horizonte : Fundação Christiano Ottoni, 1995, V1. 